\title{
Patterns of Funding Internationalisation of Higher Education. A Conceptual Framework for the Study of Internationalisation
}

\author{
Liviu Matei, Julia Iwinska and Daniela Crăciun
}

\section{Introduction}

Internationalisation of higher education is a multidimensional process. It is also a highly dynamic one (de Wit 2010; Knight 2008). While underlying long-term trends do exist (Marginson 2010), the actual manifestation of this phenomenon takes forms that are multiplying and changing in time and across countries and regions of the world (King 2010; Peck and Hanson 2014). Internationalisation has been sprouting fast, acquiring many facets, and it could be seen almost as an evolving kaleidoscopic phenomenon. This characteristic makes the study of internationalisation difficult, to the point that even defining it has become a challenging and often contested endeavour (de Wit 2010; Peck and Hanson 2014).

Nonetheless, internationalisation has been accepted as one of the most significant phenomena of our time in higher education. It is important for higher education systems, institutions, and individuals (Altbach and Knight 2007), and its momentous relevance concerns not only the broad sphere of higher education, but extends beyond its boundaries as well. It is commonly recognised, for example, that internationalisation has an impact on the development and competitiveness of national and regional economies. But internationalisation also has an impact on international relations and geopolitics (an important aspect that is often ignored, as it will be discussed in this study), migratory fluxes, or on the shape and dynamics of various aspects of social identity (also not frequently studied).

L. Matei $\cdot$ J. Iwinska $(\bowtie) \cdot$ D. Crăciun

Central European University, Budapest, Hungary

e-mail: iwinskaj@ceu.hu

L. Matei

e-mail: mateil@ceu.edu

D. Crăciun

e-mail: craciund@ceu.hu

(C) The Author(s) 2015

A. Curaj et al. (eds.), The European Higher Education Area,

DOI 10.1007/978-3-319-20877-0_14 
This perceived, or perhaps simply real importance of internationalisation has resulted in a rush toward policies or policy attempts and initiatives, devised by various actors to promote internationalisation, shape internationalisation, participate in and take advantage of this historic phenomenon. Actors include higher education institutions, groups and individuals from within such institutions, associations of universities, national public authorities (sometimes regional public authorities as well, as it will be discussed in this article), non-governmental organisations, international organisations, and the list can continue.

Internationalisation has emerged as a key topic in higher education research and policy debates in the 1990s (Gürüz 2008), when the links between higher education, and economic and social development became more apparent (van der Wende 2001). Since then, internationalisation policies have evolved from being mere ad hoc initiatives to more structured measures that have a deeper influence on the higher education systems overall (Brandenburg and de Wit 2011; Teichler 2009). Today, internationalisation is seen by some as no less than the "central motor of change" in higher education (Egron-Polak and Hudson 2014).

The amplitude of the phenomenon has been mirrored by a growing corpus of research trying to understand what internationalisation is actually about, and how to engage with, or promote it. Research on this topic, including applied policy research, is as important as it remains largely lacunar at present. The present article discusses aspects related to internationalisation that seem severely understudied to date, specifically the topic of funding of internationalisation.

The article makes a case for a study of the funding of internationalisation that can make a significant contribution to the broader understanding of the phenomenon and its consequences and effects; an understanding that hopefully goes beyond the immediately observable and somewhat trivial aspects. It is quite clear that any major endeavour in higher education would require some level of funding. In this context, one could easily claim that if internationalisation were a (or the) central motor of change in higher education, then the funding could be seen as the fuel. The investigative focus and potential relevance of this article, however, are not organised around this somewhat self-evident and not necessarily very informative truth. Rather, the article proposes a well-calibrated study attempting to identify existing patterns of funding of internationalisation in higher education that could offer fresh and relevant insights, and new factual knowledge about internationalisation, perhaps in surprising ways. Moreover, this approach could also help to better understand and refine the ways in which internationalisation is conceptualized and studied. It could help to provide elements for the definition of internationalisation and for its further study. It should be noted that this article is based on an early-stage of a comprehensive project, representing largely a literature review for the time being. Further research is planned as part of this ongoing project.

The following section presents key elements of the proposed new conceptual framework for the study of the patterns in funding of internationalisation. The relevance of this approach is also discussed along with illustrations regarding possible new insights that could be obtained from such an analysis. 


\section{A Conceptual Framework for the Study of Patterns of Funding of Internationalisation}

Although the topics of internationalisation and funding of higher education, independently, have been broadly analysed in the literature, there is room to further explore how the internationalisation of higher education has been, can, and perhaps should be financed. References to funding appear occasionally in the literature about internationalisation (Childress 2009; Throsby 1998). At the same time, there seems to be no systematic study on the funding of internationalisation, which could, nevertheless, prove very useful in several ways. It would help more than just to substantiate the common statement that "funding is important, therefore (more) funding is needed". Funding is not just a simple material condition for internationalisation, of a binary yes-no nature (i.e. no internationalisation without funding). A careful analysis shows that funding can influence-sometimes in subtle waysthe overall direction of the internationalisation process, its motivations, and key professional or ethical aspects. As it will be discussed in this chapter, the decisions on how to fund internationalisation at the national level (for example whether to incorporate it into a larger funding scheme, such as the so-called "excellence initiatives", or to include it in the funding formulae) can actually define what internationalisation is in certain contexts.

It is not difficult to accept that funding might have an impact on the effectiveness of various internationalisation activities and practices. And yet, research regarding the relationship between funding modalities (or patterns) and the effectives of internationalisation activities is severely underdeveloped, if not simply largely absent. Such systematic studies could help to find out which financial tools might work better and which do not work well for successful internationalisation.

There is not much research either on how choices are made regarding which internationalisation activities get funded. This is true for both the institutional and the system levels. The existing research, however, does indicate that the choice of what is funded is an important policy aspect to be considered, with significant practical relevance. For example, is it true that only what has economic relevance is funded in the area of internationalisation? Or perhaps only "what gets measured gets funded" in this area (Choudaha and Contreras 2014)? Whatever the answer or answers are, they would teach policy makers, university leaders, and other actors involved important practical lessons.

A systematic study of the funding of internationalisation involves asking questions such as: Who funds what? For what reason? What are the consequences of particular funding instruments and strategies? What works and what doesn't in funding of internationalisation? What works better and under which conditions? What are the policy gaps with regard to the funding of internationalisation (not only funding gaps in terms of insufficient dollar or euro amounts)?

This is already a rather long list of questions, which could be expanded a little further. This, however, might raise concerns about the feasibility of such a study. In addition, as mentioned in the introduction, internationalisation is a complex, 
multidimensional, and highly dynamic phenomenon. How can one grasp and study relevant and constant aspects in this large variety of manifestations of internationalisation? Can one identify patterns of funding and would their study be really useful?

We propose that it is possible to identify and study patterns of funding of internationalisation based on a limited number of factors or variables to begin with, as detailed below. These factors appear to represent a promising avenue for investigation. Clearly, more analysis and reflection is needed to define them (including an assessment of whether they are independent factors or not), and decide how to combine them for the purpose of building better and more complete heuristic instruments for the study of internationalisation.

Proposed factors/aspects:

1 Sources of funding of internationalisation (who funds?). Other than the important sources of funding that are usually considered in the studies of internationalisation (e.g. public authorities, institutions), a systematic scrutiny of the funding actors could identify new or neglected sources and their ways of operation.

2 Types of internationalisation activities funded (what is funded?). The types of activities funded could be identified and categorized primarily based on their motivations. A large literature about motivations is already available (de Wit 2010; Knight 2004; Kreber 2009; Qiang 2003). A study of funding patterns could even lead to the discovery of new motivations or better explain the already studied ones.

3 Scope of the internationalisation activities funded (where do funds go? - a special aspect of the question what is funded?). Internationalisation activities could be institutional, national, or international, for example. One interesting question illustrating the relevance of this factor is: who funds quality assurance elements of internationalisation initiatives, such as programs delivered abroad? (Should the government of the "exporting" institution fund quality assurance aspects or should the quality control mechanisms be developed on the side of the "importing" country? What happens to international higher education providers not certified or accredited in any particular country?) It is open for further consideration whether this should be deemed a separate factor or combined with another one (motivations).

4 Instruments of funding internationalisation (how is it funded?). The mapping and systematic study of the instruments would help to identify not only the traditional instruments, such as study abroad scholarships, but also the new or emerging tools, such as funding of internationalisation through formula-based funding or through excellence initiatives. Other funding instruments, which are relatively new in the European context, are, for example, the pan-European student loan scheme or the European pension scheme for researchers (which will also cover university academic and administrative staff to stimulate their mobility). 
5 Strategies for funding internationalisation (another aspect of the question how is it funded? and perhaps also of what is funded?). Strategies refer to how instruments are selected, combined and used, in connection with other policy objectives and funding mechanisms at institutional, national, regional level. The study of instruments and strategies for funding could help to better understand, for example, issues of effectiveness of internationalisation activities, but also how funding can influence the direction of such activities, and even the very understanding of internationalisation as a policy objective.

\subsection{Sources of Funding Internationalisation}

One claim related to funding of internationalisation that is perhaps the most often mentioned in the literature is related to funding as a barrier. The 4th IAU Global Survey (Egron-Polak and Hudson 2014) emphasizes that lack of financial resources is considered the main barrier to internationalisation. Specifically, $49 \%$ of the 1336 higher education institutions from 131 countries surveyed ranked it as first on the list of barriers. One question that can be asked in this context is who funds, and perhaps also who should fund internationalisation? Is this a task for public authorities/public funding, institutional funding, or private funding? What is the current landscape in this regard anyway? These are complex questions. On the purely descriptive dimension, the situation is different in different parts of the world. In Europe, for example, public funding is a lot more significant than in the U.S. It can be assumed, however, that in spite of this diversity, relatively stable patterns exist with regards to sources of funding internationalisation, possibly not a long list of different ones, which can be identified and studied. The limited literature already available in this area offers interesting hints.

Altbach and Knight (2007) talk about "European internationalism". This could be considered as a particular model of internationalisation. It is possible to describe this model by linking it to broader developments in higher education in Europe (e.g. the emergence of the European Higher Education Area). At the same time, if "European internationalism" is a particular model of internationalisation, it could be argued that it is so by virtue of its funding characteristics as well, including specific sources of funding. "European internationalism" exists in part because it benefits from a particular source, or sources, of funding: the EU funding. As a type of funding source, the EU funding could be defined as "regional public source" in the conceptual framework. This type of funding source (unique in the world, to date?) might explain, or contribute to explaining, the particular characteristics of the overall European model of internationalisation. It certainly helps to explain the characteristics of particular (or unique) internationalisation initiatives in this context, such as the Erasmus programs or the European pension scheme for researchers, to name only two. 
"Following the money" by looking systematically at the sources of funding of internationalisation in the European context helps to provide additional types of insight. It can be speculated, for example, that the total European funding supporting directly internationalisation activities is significantly lower than the sum of the national budgets allocated for the same purpose. Still, although the European (European Union, for the matter) funding is marginal in some cases, it does influence internationalisation activities significantly in most, if not all European countries. This situation could be conceptualized in terms of the interrelation between public national funding and regional public funding. We can discover, for example, that some countries in Europe have almost no international student mobility, except for that stimulated and funded by the EU (Matei and Iwinska 2015).

The 4th IAU Global Survey (Egron-Polak and Hudson 2014) also indicates that, at a global scale, the largest source of funding for internationalisation activities is the general institutional budget (ranked first by $53 \%$ of respondent institutions). External public funding comes second, ranked as the largest source by $24 \%$ of the respondents. Private funding from foundations and corporations is ranked as the largest source by only $4 \%$ of the respondents, as is funding from international organisations. This data is somewhat difficult to interpret completely (it is not clear, for example, what are the sources for the general institutional budget; agglutinating global data may mask, as it is rightly noted in the report, different patterns in different countries and regions of the world). It does provide, however, significant insight regarding who funds internationalisation by separating among different sources of funding. One could note here, for instance, the significant reliance on public finding in some places, or the limited role of the private funding everywhere.

If we could identify the most important sources of funding in general (categories of sources), we might be able to study patterns of funding. Moreover, it would become possible to zoom into particular situations and experiences (like in the case of the "European internationalism") and understand not only who funds in general, but also who funds what specifically, and analyse how particular sources of funding (alone or in interaction with other factors, such as types of internationalisation activities, of funding instruments) influence the orientation, nature, and impact of internationalisation activities.

\subsection{Types of Internationalisation Activities Funded (Motivations)}

The literature review conducted so far supports the conclusion that it should also be possible to identify patterns of funding of internationalisation by looking at what is funded, at the types of internationalisation activities that are funded. In particular, one could look at motivations or objectives of internationalisation activities funded. 
One of the primary motivations for internationalisation activities in higher education is income generation ("commercial motivation"). This aspect of internationalisation is perhaps among the most often studied (Altbach and Knight 2007; Kalvemark and van der Wende 1997; van der Wende 2001). The list of traditional motivations for internationalisation includes, in addition to income generation (or "profit", according to Altbach and Knight): providing international and cross-cultural perspectives for students and enhancing curricula ("traditional internationalisation"), economic and political integration ("European internationalism"), or access provision and demand absorption (Altbach and Knight 2007). Other motivations include strengthening research capacity (a well-known motivation for internationalisation, by now) or international development and capacity building (Altbach and Knight 2007; Egron-Polak and Hudson 2014). Economic development and economic competitiveness (such as training students abroad to support economic development at home, or attracting bright students from other countries to boost competitiveness at home (Findlay 2010) are also considered as part of this somewhat traditional list of motivations for internationalisation, or types of internationalisation activities.

It is possible to identify systematically what is funded, looking at the motivations of various types of internationalisation activities. The list of categories seems to be manageable, and the use of this variable could prove useful in understanding how internationalisation is funded, and how it works. In addition to descriptive elements, which are very important, one could bring into the analysis a normative perspective as well. There is already a corpus of literature that questions the appropriateness of certain motivations, in particular from an ethical perspective. This is connected to funding as well. Should public bodies fund internationalisation activities that generate brain drain, for example?

Other than the explanatory value of the analysis based on linking funding and motivations, or its normative relevance, another important aspect is its heuristic value, or the capacity to generate questions, new knowledge and insight. In presence of certain internationalisation activities, asking questions about motivations and related funding can help to expand what we know, in significant and even surprising ways.

Two examples are put forward here, which, to the best of our knowledge, have not been studied to date. One is the network of Russian-speaking ("Slavic" or "Slavonic") universities, created after the fall of the Soviet Union in several of its former republics, which are funded by the federal Russian government. A similar example is a number of universities operating in Turkish, created and funded by Turkey in other countries, from the Balkans to the Caucasus and to Central Asia. It is difficult to put these examples in any of the known categories of motivations. While research on these experiences is missing, it appears that their primary motivations are neither commercial, nor economic (although such motivations may play a certain role), they are not about inter-cultural learning, and certainly not about strengthening research. Rather, they appear to indicate a different type of motivation, which we could call geo-political. This explanation might help to understand the particular nature of these rather unusual initiatives, from a funding 
perspective as well. If in this case we combine two or three categories of funding, namely source of funding (public, but from another country), motivation (geopolitical), and eventually scope (regional/international) we could configure a particular model of internationalisation, which has not been developed before. Such an analysis may also help to shed light on particularly complex (and understudied or not studied) situations with regards to internationalisation. Such an example is the "internationalisation landscape" in Bishkek, Kyrgyzstan, which is home to several universities, including the Kyrgyz-Russian Slavic University (funded from Moscow by the Russian government and operating in Russian), the Kyrgyzstan-Turkey Manas University (a Turkish university with funds from Ankara and operating in Turkish), and the American University of Central Asia (an American-style university operating in English, benefiting from U.S.-USAID_-government money and U.S. private foundation funds). If we add locally funded Kyrgyz universities, we have the picture of something that looks very much like a geopolitical battleground, involving particular internationalisation activities and structures. Such a battleground situation is not usually studied in the mainstream literature on internationalisation.

A completely different experience regarding the involvement of the state in the creation of an entire new university (and a new model of university), while paying attention to internationalisation desiderata and objectives, is from Vietnam. The government of Vietnam created and funded the International University in Vietnam (Altbach and Knight 2007), rather than going abroad to create a university in another country or sending its own citizen elsewhere. Obviously, the motivation of the Vietnamese government in this case was not geopolitical (like in the cases of Russia and Turkey discussed above), but more directly academic, social, and economic. If political motivations where at play, there where domestic motivations (addressed in part by a decision to fund internationalisation activities with public money), rather than motivations in the domain of international relations and geopolitics.

\subsection{Types of Internationalisation Activities Funded (Geographic Scope)}

There is some discussion in the available literature that suggests another way of studying what is funded in internationalisation, namely by looking at the scope of internationalisation activities. As Knight (2004) highlights, very often a distinction is made between institutional aspects of internationalisation (institutional strategies, mechanisms, and activities) and national aspects (national strategies, policies, or activities). One could also add, at least tentatively and subject to confirmation and refining through further research, internationalisation activities and aspects that are regional in their scope. The emergence of the European Higher Education Area and the developments in the European Union in higher education for the past 20 25 years are a good illustration for the regional scope category. Other examples 
could be the Visegrad Group (consisting of the Czech Republic, Hungary, Poland, and Slovakia ${ }^{1}$, which has launched initiatives aiming at promoting specific aspects of internationalisation among the member countries and extending them slightly to the neighbouring countries, or the Nordplus cooperation among the Baltic and Nordic countries. ${ }^{2}$ An example from outside of Europe could be the Association of Southeast Asian Nations (ASEAN), whose cooperation is developing dynamically, including aspects relevant from the internationalisation perspective.

All examples from Europe already include specific funding policies and mechanisms that have been created to support these regional initiatives. The Nordplus total budget in 2014 was 9 million EUR, while the International Visegrad Fund had a total budget of 8 million EUR. In all cases, particular strategic approaches, with clear "motivations" and "sources", but also targeted funding, have helped to generate new dynamics in internationalisation, supporting a regional perspective.

Ignoring the "geographic scope" factor in the proposed analysis would make it very difficult to understand such developments. At a more general level, these examples show that using the "geographic scope" factor in identifying funding patterns helps systematise the variety of internationalisation practices and experiences in the world, as well as their impact and outcomes. The examples of regional cooperation models from Europe provide a vast and complex material for study of the patterns of funding of internationalisation, all the way from funding mobility to funding quality assurance, or from funding access to funding equity in internationalisation.

One interesting question that could be asked in this context is whether one could speak of internationalisation activities that are simply or primarily international, and therefore neither institutional, nor national or regional. This question is asked considering the existence of actors that are not anchored in national or regional legal contexts, and are not higher education institutions either. There are serious concerns for quality linked to the expansion of internationalisation (Broadbent and Middlehurst 2013). The need for quality certification (like accreditation of cross-border provisions) is not at present fully addressed by national structures or formal international structures and organisations. Some space has been created in this way for genuinely "international actors" who act "internationally", whether they are bona fide or just dubious, if not simply fake "certification mills" (a new industry emerging like the one of fake diploma mills) (Altbach et al. 2009). How such genuinely international activities (which could not be considered institutional, national or regional) are funded, can also shed light on this aspect of internationalisation. This is a potential additional argument for the more general point made here regarding the relevance of "scope" as a factor to be used for the construction of a conceptual framework for the study of patterns of funding the internationalisation of higher education.

\footnotetext{
${ }^{1}$ See http://visegradfund.org/about/basic-facts.

${ }^{2}$ See http://www.nordplusonline.org/ or http://www.nordplusonline.org/Who-can-apply/NordplusHigher-Education.
} 


\subsection{Instruments of Funding}

What could be the usefulness of a systematic scrutiny of instruments of funding internationalisation?

Some of the more traditional instruments of funding of internationalisation have been studied extensively, for example, state scholarships to study abroad. Among the most impressive research in this area is the study by Perna et al. (2014) looking at how scholarships abroad serve to build human capital at national level. This study is extremely informative as it goes beyond the few relatively well-known experiences with government-funded scholarships in Kazakhstan and Brazil, or Norway in Europe (183 government-sponsored international scholarship programmes worldwide are analysed).

One could also look at the newer, emerging, or less traditional instruments of funding to understand how internationalisation activities, and even the understanding of internationalisation, evolve.

The DEFINE project led by the European University Association (EUA) published very informative reports focusing on the strategies for efficient funding and funding for excellence for universities in Europe. The reports (Estermann et al. 2013; Bennetot-Pruvot and Estermann 2014) are very useful for understanding the situation with regards to public funding in Europe. Although not intended as a study about internationalisation, the reports provide interesting insights regarding two instruments for funding internationalisation: excellence funding and funding formulae.

A number of European countries have used in the last several years a special funding instrument which consists of making available significant additional public funding for a limited number of universities, so as to promote excellence in these universities or, indirectly, across the system, expected to be reflected in better research, increased international competitiveness, and in some cases higher ranking positions as well. The amounts mobilized by national authorities are significant: 7.7 billion EUR altogether in France, and 750 million EUR in Russia for a period of four years, to give only two examples. What is interesting for the purpose of our discussion is that, at least in some of these countries, one explicit objective of the excellence funding was "fostering cooperation among research actors, and further internationalisation of the higher education institutions" (Bennetot-Pruvot and Estermann 2014). In other words, the thinking behind this instrument of funding envisages internationalisation almost as an objective in itself, rather than only as a means. This is relevant for the purpose of our article because it shows how using funding instruments can help as a heuristic to analyse and understand evolving conceptions on internationalisation. In this case, internationalisation as related to excellence (in research primarily) becomes almost, if not simply, an objective in itself rather than a means.

One could also discuss here how funding instruments influence the nature, or direction of internationalisation activities. The funding of the excellence initiatives is heavily oriented towards research, with a lot less attention (or money) for 
teaching. Given the significance of the funding involved (usually really large amounts), as well as the public prominence of the overall initiative in all these countries, this "mere" instrument of funding influenced indeed the orientation, focus, and nature of internationalisation activities. In other words, the direct "bias" towards financing research changed the more generic understanding of internationalisation (understanding is largely and primarily about research now).

Another interesting finding of the DEFINE project, relevant in this context, is that funding formulae represent an instrument for funding internationalisation. In several European countries indicators for the allocation of public funding include explicit references to internationalisation aspects, such as the number of international students or international staff in the respective institution (Estermann et al. 2013). In Denmark, a so-called "international taximeter" method was founded, serving to allocate a certain fix amount per outgoing and incoming international student. In Finland, the internationalisation-related criteria for allocation of public funding (including for teaching and research personnel) account for $9 \%$ of the public funding.

Such examples reaffirm that the study of instruments for funding internationalisation helps to understand internationalisation more generally. In these cases, the inclusion of internationalisation-related criteria in the core formulae for the allocation of public funding indicates a kind of mainstreaming of internationalisation, at least as a policy desideratum. Rather than $a d$ hoc or would-be internationalisation activities, policy makers in these countries look at internationalisation as a core characteristic of the work of universities and of the higher education systems overall.

We could further illustrate the point by discussing other instruments of funding internationalisation activities. In the European context, one of the most innovative such instruments is the plan (in an advanced phase of preparation) of the EU Commission to launch a Pan-European Pension Fund for researchers (see for example Kelly 2015). The Fund is meant to support the mobility of "researchers", but also of academic and administrative university personnel, within the European Research Area. This type of mobility (a political objective in the EU) is otherwise hindered by different national regulatory systems, many of which penalize cross-border mobility when it comes to pension benefits. This is an example of a new funding mechanism which does not address traditional issues of "available funding" for internationalisation, but is rather designed in a novel way to counter legal provisions and regulations that have adverse financial implications on the international (or regional, here) mobility of university staff.

In sum, using funding instruments as a tool for studying internationalisation appears to be both relevant and feasible. The identification and study of instruments of funding could contribute to identifying patterns of funding. Patterns of funding, in turn, make it possible to gain relevant insight about internationalisation in a systematic manner, while avoiding the feeling of disorientation that might otherwise arise when confronted with the large and ever evolving variety of internationalisation experiences and facets. 


\subsection{Funding Strategies}

When trying to identify and study patterns of funding of internationalisation, one could look not only at individual funding instruments, but also at funding strategies at institutional, national, or regional level. Strategies could include principles for funding, instruments and methods, institutions or agencies with particular responsibilities in this area (for the national or regional level), or units (in the case of higher education institutions).

We have undertaken a comparative analysis of national strategies with regards to internationalisation in several European countries in another study (Matei and Iwinska 2015). That analysis showed that studying national internationalisation strategies with attention to their funding aspects (or "funding strategies") is particularly informative to understand the key characteristics of internationalisation activities in a given country. Moreover, it allows understanding and perhaps even predicting the impact of various internationalisation activities.

Funding strategies can be identified and studied at institutional level as well. Where they exist, they usually make a difference. A comparative study by Childress (2009) offers a very good illustration of how different institutional strategies (e.g. differential allocation of resources) have an impact on the successful involvement of the faculty in internationalisation activities.

It can be expected that institutional strategies for the funding of internationalisation, where they exist, can be studied without significant difficulties. On the national level, however, it might be more challenging because funding relevant for internationalisation can be traced in a number of different policy approaches (e.g. related to economic development, competitiveness, labour, migration/immigration, foreign trade, etc.). Therefore, in studying the patterns of funding of internationalisation, one also needs to pay attention to policies, or measures that are not directly or explicitly aimed at supporting or influencing internationalisation. A recent example is discussed below to illustrate the complexity of the issue. Many other examples exist and can be reviewed.

Recently, two decisions with regards to funding (not funding of internationalisation per se) taken by the government of England have been expected by some higher education scholars or university administrators to have a very significant impact on internationalisation aspects, in particular on student mobility (Broadbent and Middlehurst 2013; Greennway 2012). The measures were adopted primarily in order to change the funding system for undergraduate students by shifting a large part of the cost burden on students themselves and their families, rather than on taxpayers. A related reason was to permit the growth of individual budgets of universities, while reducing the proportion of funding that comes from public sources. One of these decisions refers to the change in the maximum level of the tuition fee that could be charged for undergraduate studies (currently 9000 GBP), linked with the introduction of a broad and easy to access income-contingent student-loan mechanism. The other one is about the use of the same standards and rules with regard to tuition fees and student loans that apply to domestic students, 
for all foreign students who are EU-citizens (this is in fact in line with European legislation). If the EU citizens are treated in the same way for the purpose of tuition fee payments (same cap) and student loans (same conditions), in turn, there was no government-imposed cap on tuition fees to be charged to non-EU students, which makes it possible for universities to raise tuition fees significantly above 9000 GBP for this group of students, without possibility to access the student loan mechanism.

These decisions, put in practice only recently (beginning with 2012 for the new tuition fee cap) were feared to have an impact on the flux of incoming students from other countries, and also on outgoing students. With undergraduate studies becoming more expensive in England, in fact at least nominally the most expensive in Europe, some expected an exodus of English students to other countries and also a loss of students from other countries coming to England (Greenway, 2012). It appears, however, that this was not the case. No exodus of students going out of England was reported and the number of students coming to England from the EU and from outside the EU did not go down, quite the contrary (Higher Education Statistics Agency 2014). One possible explanation for the fact that the anticipated reaction (higher outgoing and lower incoming student flows) has not happened could be that it is simply too early to see the effects of these measures. Another explanation, however, is that there are other factors that matter in this case, which are more important than tuition fees or compensate their expected negative effects. One such factor is the easily accessible loan system (for all EU, including UK, students). Under this system, domestic and international EU students can receive almost automatically a loan covering their tuition fee, which they will repay after graduation (if at all, for some of them) at a variable rate contingent upon the level of their income. In other words, students do not feel directly and immediately the burden of the higher tuition costs, and they may not have clear representation about how this would affect their financial situation in the future, after graduation. For non-EU students, it appears that despite a higher cost, getting a higher education diploma in the UK remains attractive, for the diploma itself, but also for other reasons, such as the possibility to remain and work in England (or the UK) after graduation.

This example is in a way about how anticipated effects on internationalisation of decisions on funding strategies and instruments have not materialized (effects that could have happened, but have not happened, at least as yet). It does show however, the relevance of looking at funding strategies that are not introduced specifically in relation to internationalization.

\section{Conclusions}

This exploratory paper brings up a seemingly obvious and yet complex and not sufficiently analysed aspect of the internationalisation phenomenon, namely funding. It argues that despite complexities, it is possible to study internationalisation from a novel perspective, with funding-related questions at the core. 
The article outlines a preliminary conceptual framework of how such a study could be structured and identifies five key factors for funding of internationalisation. The proposed factors are:

- Sources of funding -Who funds internationalisation?

- Types of activities funded-What gets funding?

- Geographic scope of funding-Where is the funding going?

- Funding instruments-How is it funded?

- Funding strategies-What strategies are funding it?

The claim that internationalisation can be studied in a novel and productive manner (by identifying patterns of funding in this area that consider a small number of identifiable factors or parameters) appears to be at least partly supported by the arguments, data, and analyses provided in the paper, building on the proposed new conceptual framework. Significant more work is needed to further develop this approach and to put its intuitions and conjectures to test. It appears however, that this is a very interesting avenue for future research in the area of internationalisation.

Open Access This chapter is distributed under the terms of the Creative Commons Attribution Noncommercial License, which permits any noncommercial use, distribution, and reproduction in any medium, provided the original author(s) and source are credited.

\section{References}

Altbach, P. G., \& Knight, J. (2007). The internationalization of higher education: Motivations and realities. Journal of Studies in International Education, 2007(11), 290-305.

Altbach, P. G., Reisberg, L., \& Rumbley, L. E. (2009). Trends in global higher education: Tracking an academic revolution. Paris: UNESCO.

Bennetot-Pruvot, E. \& Estermann. T. (2014). Define thematic report: funding for excellence. Brussles: European University Association.

Brandenburg, U., \& de Wit, H. (2011). The end of internationalization. International Higher Education, 62, 15-17.

Broadbent, J., \& Middlehurst, R. (2013). Internationalisation and private engagement in higher education: Introduction. Public Money \& Management, 33(2), 83-90.

Childress, L. (2009). Planning for internationalization by investing in faculty. Journal of International and Global Studies, 1(1), 30-49.

Choudaha, R., \& Contreras, E. (2014). HE internationalisation - What gets measured, gets funded. University World News, 327, 04 July 2014.

de Wit, H. (2010). Internationalisation of higher education in Europe and its assessment, trends and issues. Retrieved from accessed at http://www.nvao.net/page/downloads/ Internationalisation_of_Higher_Education_in_Europe_DEF_december_2010.pdf

Egron-Polak, E., \& Hudson, R. (2014). Internationalisation of higher education: Growing expectation, fundamental values. IAU 4th global survey. International Association of Universities.

Estermann, T., Bennetot-Pruvot, E., \& Clayes-Kulik, A.-L. (2013). Designing strategies for efficient funding of higher education in Europe. DEFINE interim report: European University Association. 
Findlay, A. M. (2010). An assessment of supply and demand-side theorizations of international student mobility. International Migration, 49(2), 162-190.

Greennway, D. (2012). The global financial crisis and the internationalisation of higher education UoN blogs/knowledge without borders. July 25, 2012. Retrieved from http://blogs.nottingham. ac.uk/vice-chancellor/2012/01/20/the-global-financial-crisis-and-the-internationalisation-ofhigher-education

Gürüz, K. (2008). Higher education and international student mobility in the global knowledge economy. Albany: State University of New York Press.

Higher Education Statistics Agency. (2014). Higher education student enrollments and qualifications obtained at higher education providers in the United Kingdom 2013/2014. Retrieved from https://www.hesa.ac.uk/sfr210

Kalvemark, T., \& van der Wende, M. (1997). National policies for the internationalization of higher education in Europe. Stockholm: Hogskoleverket.

Kelly, E. (2015). European commission launches international pension scheme for researchers. Science|Business, January 2015. Accessed at http://www.sciencebusiness.net/news/76855/ European-Commission-launches-international-pension-scheme-for-researchers

King, R. (2010). Policy internationalization, national variety, and governance: global models and network power in higher education states. Higher Education, 60(585), 594.

Knight, J. (2004). Internationalization remodelled: Definition, approaches, and rationales. Journal of Studies in International Education, 8(1), 5-31.

Knight, J. (2008). Higher education in Turmoil. The changing world of internationalisation. Rotterdam: Sense Publishers.

Kreber, C. (2009). Different perspectives on internationalization in higher education. New Directions for Teaching and Learning, 118, 1-14.

Marginson, S. (2010). Trends in the internationalisation of higher education: The new dynamism of global action prepared for the internationalization of higher education conference Madrid, Apr 19-20. Retrieved from http://www.oapee.es/dctm/eu2010/19y20deabril/conferenceihesi monmarginson.pdf?documentId=0901e72b800d7f99

Matei, L., \& Iwinska, J. (2015). National strategies and practices in internationalisation of higher education: Lessons from a cross-country comparison. In A. Curaj, L. Deca, E. Egron-Polak \& J. Salmi (Eds.), Higher education reforms in Romania between the Bologna process and national challenges. Berlin: Springer.

Peck, J. M., \& Hanson, S. E. (2014). Introduction to Globalization of International Education. IIE Networker, Spring 2014, pp. 21-23.

Perna, L. W., Orosz, K., Gopaul, B., Jumakulov, Z., Ashirbekov, A., \& Kishkentayeva, M. (2014). Promoting human capital development: A typology of international scholarship programs in higher education. Educational Researcher, 43(2), 63-73.

Qiang, Z. (2003). Internationalization of higher education: Towards a conceptual framework. Policy Futures in Education, 10(2), 248-270.

Teichler, U. (2009). Internationalization of higher education: European experiences. Asia Pacific Education Review, 10, 93-106.

Throsby, D. (1998). Financing and effects of internationalisation in higher education: The economic costs and benefits of international student flows.

van der Wende, M. C. (2001). Internationalization policies: About new trends and contrasting paradigms, 14, 249-259. 